\title{
The perception of the illness and the self-efficacy in the management of emotions in cardiac patients
}

\author{
Cristina Marogna, ${ }^{1}$ Sofia Elena Russo, ${ }^{1}$ Floriana Caccamo, ${ }^{1}$ Alessandro Pinton, ${ }^{2}$ Vito Sava, ${ }^{2}$ Roberto Carlon ${ }^{2}$ \\ ${ }^{1}$ Department of Philosophy, Sociology, Pedagogy and Applied Psychology, University of Padua; ${ }^{2}$ UOA of Cardiology, Rehabilitation \\ Cardiology, ASSL 6 "Euganea", Presidio Hospital of Cittadella (PD), Italy
}

\begin{abstract}
Cardiac rehabilitation is the sum of psychological, physical and social treatments that are offered to cardiac patients to maintain or regain an active position in society. This study wants to evaluate changes in the perception of the illness and in the self-efficacy of the management of positive and negative emotions in patients who went through cardiac rehabilitation. Sixty-seven patients (20 females, 47 males) were selected within the cardiac rehabilitation unit in the Hospital of Cittadella (Italy). Illness Perception Questionnaire - revised version and the Scale for the self-efficacy of the management of positive and negative emotions were submitted at the beginning and at the end of the rehabilitation program. One-way analyses-of-variance were performed to evaluate different answers in questionnaires between pre- and post-evaluation, and to explore gender differences. A significant change was found in the perception of duration of illness, perceived as permanent and longer after the cardiac rehabilitation program. Furthermore, at the end of the cardiac rehabilitation program men perceived the illness more chronic than women, even if they are less worried and anxious. Intensive cardiac rehabilitation has a great emotional impact on cardiac patients, in-

Correspondence: Floriana Caccamo, Department of Philosophy, Sociology, Pedagogy and Applied Psychology, University of Padua, via Venezia 12, 35124 Padua, Italy.

E-mail: floriana.caccamo@unipd.it fluencing their perception and management of the illness. Working on emotions, through psychological groups, helps patients change their beliefs by offering them a different perspective to approach the illness.
\end{abstract}

Acknowledgments: the authors gratefully acknowledge the support of all personnel and the care team of the Cardiac Rehabilitation program of Presidio Hospital of Cittadella. In particular, the authors express their gratitude to the doctors, nurses, psychologists, dietitians, physical therapists and trainees who have welcomed and encouraged the implementation of this study.

Citation: Marogna, C., Russo, S. E., Caccamo, F., Pinton, A., Sava, V., \& Carlon, R. (2018). The perception of the illness and the selfefficacy in the management of emotions in cardiac patients. Research in Psychotherapy: Psychopathology, Process and Outcome, 21(3), 201-208. doi: 10.4081/ripppo.2018.310

Contributions: CM, RC, FC and VS conceived and designed the study; they also supervised the data collection. SER and AP collected the data. FC was responsible for the statistical design of the study and for carrying out the statistical analysis. SER, FC and CM wrote the article. All the authors have critically revised the article and have approved the final version.

Conflict of interest: the authors declare no potential conflict of interest.

Funding: none.

Received for publication: 4 May 2018.

Revision received: 21 September 2018.

Accepted for publication: 4 October 2018.

This work is licensed under a Creative Commons Attribution NonCommercial 4.0 License (CC BY-NC 4.0).

CCopyright C. Marogna et al., 2018

Licensee PAGEPress, Italy

Research in Psychotherapy.

Psychopathology, Process and Outcome 2018; 21:201-208

doi:10.4081/ripppo.2018.310
Key words: Perception of illness; Positive and negative emotions; Cardiac rehabilitation; Beliefs.

\section{Introduction}

Cardiac Rehabilitation (CR) is a clinically useful method of treatment that modifies cardiac risk factors, reduces psychological distress after an acute cardiac event and determines a significant improvement in overall quality of life (Freitas et al., 2011; Lavie \& Milani, 2006; Pourafkari et al., 2016). CR was defined as the coordinated sum of activities required to influence favourably the underlying cause of cardiovascular disease, as well as to provide the best possible physical, mental and social conditions, so that the patients may, by their own efforts, preserve or resume optimal functioning in their community and through improved health behaviour, slow or reverse progression of disease (Lespérance \& Frasure-Smith, 2000; Mozafari, Baharvand, Mohebi, \& Hejazi, 2016).

As part of secondary rehabilitation, people may be offered interventions which specifically aim to influence psychological or psychosocial outcomes, as quality of life, sense of self-efficacy, management of positive and negative emotions (Piepoli et al., 2014). These psychological or psychosocial interventions are varied and may range from organizational efforts to improve patient communication and support, to empirically supported psychotherapies used to target diagnosed psychopathology in people with cardiac conditions. 
CR results from the sum of psychological, physical and social treatments that are offered to the cardiac patients to maintain or regain an active role in society (Griffo et al., 2008). The ultimate objective of CR is to progressively rehabilitate patients to make them feel healthier, prevent new cardiac episodes and hence reduce the probability of hospital admission (Carlson et al., 2001; French, Cooper, \& Weinman, 2006).

Recent studies show the effectiveness of psychological support group treatment in cardiac patients (Caccamo et al., 2018). Group treatment not only allows sharing problems, including interpersonal conflicts, life transitions concerns and grief but it also addresses social isolation, a factor that was associated with an increased mortality and morbidity in some studies of patients with post-acute or chronic heart disease (Rutledge, Redwine, Linke, \& Mills, 2013).

The psychological group, also helps patients to have a more realistic perception of their cardiac disease, a better control of emotions and an enhanced capacity for managing negative emotions (Petrie, Jago, \& Devcich, 2007; Scholz, Sniehotta, \& Schwarzer, 2005; Yalom \& Leszcz, 2005). Being able to picture a more realistic image of themselves truly helps patients to overcome difficulties, accept their condition and live with it (Griffo, 2010; Morgan, Villiers-Tuthill, Barker, \& McGee, 2014). This holistic approach eventually leads to a better perception of the self and the effectiveness of personal actions (Balestroni \& Giannuzzi, 2010; Keteyian, Squires, Ades, \& Thomas, 2014).

\section{Purpose of the present study}

The purpose of the present study is to determine whether a short-term 4-week Cardiac Rehabilitation program can modify illness beliefs and self-efficacy in management of emotions in cardiac patients after an acute cardiac event. It has been hypothesized to find less wrong beliefs related to heart disease and a higher perception of self-efficacy in the management of positive and negative emotions. In addition, we aimed to study gender differences in psychological outcomes before and after CR.

\section{Materials and Methods}

\section{Procedure section}

This study received the approval of Padua University's Psychological Ethical Committee (Number 2000/2016), and the questionnaires administration was done from October 2016 to April 2017. Patients were recruited at the operating unit of Cardiology, in the Hospital of Cittadella (Italy). The protocol was proposed to all patients referred for an outpatient CR program after an acute event (ischemic heart disease with or without subsequent myocardial revascularization, chronic heart failure, chronic occlusive peripheral arterial disease, heart transplantation), who attended a 4-week intensive rehabilitation pro- gram. Patients with an extended program, reserved for the most compromised patients (mainly those with chronic heart failure and patients unable to participate due to family, work or logistic issues) were excluded. The exclusion criteria included the inability to read or understand Italian, visual or auditory impairments, incomplete data collection, life-threatening conditions and the presence of a neurological deficit.

Questionnaires were administered by two psychologists at the beginning of rehabilitation (T0: pre-test) and at the end, after four weeks (T1: post-test). Each patient signed an informed consent, checked and approved by the Ethics Committee of University of Padua.

\section{Cardiac rehabilitation treatment program}

The program is characterized by five fundamental activities. Initially, the patients are subjected to all those cardiac surveys necessary for a better evaluation of their post-acute condition. Secondly, given that recent studies have found a reduction in depressive symptoms, cardiovascular mortality and hospitalization rates with the introduction of physical activity in CR programs, they are led to a period of personal physical training resulting in an overall improvement in their quality of life (Herring, Puetz, O'Connor, \& Dishman, 2012). The third activity is health education aiming at increasing patients' resources and self-management skills to correct their personal beliefs, which can be erroneous. This activity also improves compliance, prevents relapses and hospitalizations, raises awareness of the problem and encourages continuous monitoring, even in asymptomatic subjects with cardiovascular disease. In addition, group meetings with a dietician are provided to start healthy eating programs mainly based on the Mediterranean diet. Finally, a group of psychological support is provided, because any cardiac event involves a high psychological stress that if prolonged, in addition to worsen the quality of life, may cause an increased risk of further cardiovascular events. The group, led by a psychodynamic psychotherapist, is a homogeneous open group of about 8 patients per session that meets once a week. The psychotherapist has a specific training on group psychotherapy and on the management of groups of patients with physical diseases, in addition to the therapist there are also a nurse and a trainee psychologist. The psychological support group offers patients a space dedicated to reflection on their own disease, allowing them to share their deepest anxieties and to understand how to live with the disease (Caccamo et al., 2018). During the group meetings, patients meet other patients who lived similar experiences and this increases the perception of social support and the reassurance that comes with it (Yalom \& Leszcz, 2005). There are also individual psychological/psychotherapeutic talks aimed to patients who require further investigation, or patients reported by nurses.

The group is a specialized therapeutic group whose aim is to help patients comprehend their medical condi- 
tion and discover more about its symptoms. The goal is changing patients' perception of life and their approach to it (Da Vico et al., 2014; Molinari, Compare, \& Parati, 2007). The group psychotherapist tries to support the patients and help them manage their perceived feelings and emotions, caused by their heart disease condition (Dis, 2003; Ghedin et al., 2017), through support interventions. For example, to the following thoughts of a patient What happens with the passage of time in an uninhabited house? If there is no one who can take care of it, it will surely fall apart. It is a part of the heart that slowly crumbles. When you have a big feeling, you feel it inside, it's not like it passes through you. You're bad in your underwear. Your home suffers - this was the psychotherapist intervention-Before restoring the house you have to put some props. Before closing the cracks and giving the plaster to the walls it is necessary to provide the house with an additional support so that it does not collapse while trying to fix it.

\section{Participants}

All the patients voluntarily accepted to participate in the study. Among the 74 patients enrolled, two patients dropped out from the rehabilitation program for personal reasons and five patients were excluded from the analysis because they did not complete the post-test evaluation. Therefore, a total of 67 patients were included in the analysis. The definitive sample consisted of 67 patients (20 females and 47 males). Their average age was 65.02 (range 43-82, $\mathrm{SD}=9.82$ ).

\section{Instruments}

The instruments used were the Illness Perception Questionnaire - revised version (IPQ-R, Italian validation by Giardini, Majani, Pierobon, Gremigni, \& Catapano, 2007; Moss-Morris et al., 2002) and the Scale for the selfefficacy of the management of positive and negative emotions (Caprara, 2001).

The IPQ-R was used to investigate the various perceptions of illness. It allows the drawing of a reasonably clear picture of the mental representation of illness the patients form in their mind, starting from what they know about the pathology (Giardini et al., 2007). This tool is based on Leventhal theory (Leventhal \& Cameron, 1987). The theory states that an individual can handle puzzling situations and particularly react dynamically to a disease thanks to interpretation, which in turn provides emotional answers. To summarize, the way in which the patients picture their condition, affects the way they face it.

IPQ-R assesses eight domains of disease: identity (not reported), duration (acute/chronic), consequences, personal control, treatment control, illness coherence, timeline cyclical and emotional representations.

These seven domains are described through 38 items, put at random in the questionnaire and labelled through the Likert scale made of five points. Items are added for each domain with the following range scores: duration from 0 to 24, consequences from 0 to 24, personal control from 0 to 24, treatment control from 0 to 20 , illness coherence from 0 to 20 , timeline cyclical from 0 to 16 , emotional representations from 0 to 24 . Higher scores suggest greater beliefs in each domain.

The Scale for the self-efficacy of the management of positive and negative emotions (Caprara, 2001) is a selfreport questionnaire of fifteen items divided into two subscales: 8 items measure negative emotions and 7 items measure positive emotions. The evaluation is done with a Likert scale of five points. Scoring consists in the result of the sum of the first 8 items (range scores 8-40) where high scores describe the perception of a greater ability to overcome injuries suffered, manage any criticism received and manage other negative emotions. High scores in the other subscale of 7 items (range scores 7-35) describe the perception of a greater ability to manage positive emotions, enjoy one's own successes and express happiness about their own life.

\section{Data analysis}

Statistical package SPSS 22.0 was used for statistical analysis. We used repeated measures (ANOVA) to find differences in illness beliefs and self-efficacy in management emotions between pre and post-evaluation. ANOVA one-way was performed to explore gender differences in variables studied. A P-value of 0.05 or less was considered to indicate statistical significance.

Both instruments showed good reliability and internal consistency both at pre-test and at post-test evaluation. More specifically, the results showed what follows: IPQR pre-test $(\alpha=.786)$ and post-test $(\alpha=.780)$; scale for the self-efficacy of the management of positive and negative emotions pre-test $(\alpha=.809)$ and post-test $(\alpha=.740)$.

\section{Results}

Repeated measures ANOVA determined that the mean in the Duration domain (IPQ-R) differed significantly between pre and post-evaluation $\left(F_{(1,66)}=6.95, \mathrm{P}<0.005\right)$, specifically average scores are higher at the end of the CR program indicating that patients perceived their illness as a permanent and lasting situation at the end of the CR program in comparison with the perception they had before starting the CR path (Table 1).

About the Self-Efficacy Scale in the management of positive and negative emotions, no statistically significant difference is detected between the first and the second administration. However, considering the average scores from a qualitative point of view, a difference between the two administrations is detected both in the negative emotions subscale $(\mathrm{M}(\mathrm{T} 0)=29.76 ; \mathrm{M}(\mathrm{T} 1)=30.01)$ and in the positive emotions subscale $(\mathrm{M}(\mathrm{T} 0)=30.73 ; \mathrm{M}(\mathrm{T} 1)=31.80)$, indicat- 
ing a greater perception of self-efficacy in the management of positive and negative emotions (Table 2).

One-way ANOVA was performed to verify gender differences in illness beliefs (Table 3) and in Self- efficacy in the management of positive and negative emotions (Table 4). It resulted a gender difference at post-evaluation (T1) in Duration domain (IPQ-R) where men (M=16.57, $\mathrm{SD}=3.93)$ obtained higher scores than women $(\mathrm{M}=14.10$, $\mathrm{SD}=3.88$ ) and in Emotional representations where women $(\mathrm{M}=11.55, \mathrm{SD}=4.37)$ obtained higher scores than men $(\mathrm{M}=8.55, \mathrm{SD}=3.31)$.

\section{Discussion}

Cardiac rehabilitation combines physical activity with risk factors' modification and, within a perspective of secondary prevention, aims to reduce symptoms related to the disease and the risk of new cardiovascular events, to improve the physical exercise capacity, to reduce disability and to improve re-employment (Freitas et al., 2011; Mozafari et al., 2016).

This study wishes to evaluate if a short-term 4-week Cardiac Rehabilitation program can modify illness beliefs and self-efficacy in management of positive and negative emotions. Results showed a statistic difference in the perception of the duration of the disease that patients have at the end of the CR program. Regarding the perception of duration, patients perceive their medical condition as a permanent and long-lasting situation, which they should take care of for the rest of their lives. This perception is different from that at the beginning of the CR program, as through the different activities of the program (meetings with nurses, dietician, physical activity and psychological group) patients acquire new information and knowledge about the disease, the lifestyle that they should have and on the most useful eating habits for them. This set of notions and the comparison with others patients allow them to become more responsible for their health by not underestimating the acute cardiac event they suffered.

Exploring gender differences at pre and post-evaluation, it resulted that at the end of CR program men perceived their illness to be a more unpredictable and more chronic medical condition than what women perceived. At the same time, they are less worried about their illness compared to women, who instead show more concern and fear about their medical condition. These discrepancies picture a difference between gender in the strategies adopted as a reaction to the cardiac event, women seem to perceive a greater impact of heart disease in their lives, and this leads them to have more anxiety, more worries and fears in managing it,

Table 1. Illness beliefs (IPQ-R) before $\left(\mathrm{T}_{0}\right)$ and after $\left(\mathrm{T}_{1}\right)$ cardiac rehabilitation.

\begin{tabular}{|c|c|c|c|c|c|}
\hline IPQ-R & Administration & Mean & SD & $\mathbf{F}$ & $\mathbf{P}$ \\
\hline Duration & $\begin{array}{l}\mathrm{T}_{0} \\
\mathrm{~T}_{1}\end{array}$ & $\begin{array}{l}14.07 \\
15.83\end{array}$ & $\begin{array}{l}4.85 \\
4.35\end{array}$ & 6.95 & .010 \\
\hline Consequences & $\begin{array}{l}\mathrm{T}_{0} \\
\mathrm{~T}_{1}\end{array}$ & $\begin{array}{l}12.31 \\
11.76\end{array}$ & $\begin{array}{l}4.02 \\
3.37\end{array}$ & .516 & .475 \\
\hline Personal control & $\begin{array}{l}\mathrm{T}_{0} \\
\mathrm{~T}_{1}\end{array}$ & $\begin{array}{l}17.62 \\
18.40\end{array}$ & $\begin{array}{l}3.13 \\
2.35\end{array}$ & .360 & .850 \\
\hline Treatment control & $\begin{array}{l}\mathrm{T}_{0} \\
\mathrm{~T}_{1}\end{array}$ & $\begin{array}{l}15.47 \\
15.94\end{array}$ & $\begin{array}{l}2.10 \\
1.98\end{array}$ & .864 & .356 \\
\hline Illness coherence & $\begin{array}{l}\mathrm{T}_{0} \\
\mathrm{~T}_{1} \\
\end{array}$ & $\begin{array}{l}13.31 \\
14.00\end{array}$ & $\begin{array}{l}3.41 \\
2.80\end{array}$ & 1.93 & .170 \\
\hline Timeline cyclical & $\begin{array}{l}\mathrm{T}_{0} \\
\mathrm{~T}_{1} \\
\end{array}$ & $\begin{array}{l}5.52 \\
5.74\end{array}$ & $\begin{array}{l}2.57 \\
2.25\end{array}$ & 1.91 & .171 \\
\hline Emotional representations & $\begin{array}{l}\mathrm{T}_{0} \\
\mathrm{~T}_{1}\end{array}$ & $\begin{array}{c}10.04 \\
9.65\end{array}$ & $\begin{array}{l}4.40 \\
3.83\end{array}$ & 1.97 & .165 \\
\hline
\end{tabular}

IPQ-R, Illness Perception Questionnaire - revised version.

Table 2. Self-efficacy in the management of positive and negative emotions before $\left(T_{0}\right)$ and after $\left(T_{1}\right)$ cardiac rehabilitation.

\begin{tabular}{lccccc}
\hline $\begin{array}{l}\text { Self-efficacy scale in the management of positive } \\
\text { and negative emotions }\end{array}$ & Administration & Mean & SD & F & P \\
\hline Negative emotions & $\mathrm{T}_{0}$ & 29.76 & 6.38 & 1.06 & .306 \\
& $\mathrm{~T}_{1}$ & 30.01 & 6.74 & .515 & .476 \\
\hline Positive emotions & $\mathrm{T}_{0}$ & 30.73 & 5.26 & 4.83 & \\
\end{tabular}


as confirmed in previous studies (Aalto, Heimans, Weinman, \& Aro, 2005; Grace et al., 2005).

The rehabilitation program allows the patients to change the way in which they live with the disease, thanks to constant comparison with fellow patients (Pogosova et al., 2015). The psychological group could stimulate the development of protective factors, which are essential for the achievement of an improvement of the quality of life in cardiac patients (French et al., 2006; Scholz et al., 2005).

Cardiac rehabilitation causes the patients to change and to be able to better regulate and recognize what they are experiencing. The pattern of habits the patient had before entering the rehabilitation program, which consisted on false beliefs, is now eradicated. This enables to set free the patients from what they feel (fear, terror, insecurity) and to reach different and higher levels of emotion and awareness (Biondi-Zoccai et al., 2016). During rehabilitation, patients are given the opportunity to create a new portrait of themselves, a more tangible and realistic one: this portrait both helps and discourages the patients because they find themselves facing the truth of being survivors of a heart attack that worsened their quality of life (Dahlke, 2015). The psychological support guaranteed to the patient proves to be efficient even in the emotional response of the individual, who succeeds in better managing negative emotions such as fear, anger and nervousness caused by a more realistic perception of the illness (De Isabella \& Majani, 2015).

Studies showed that there is a significant connection between heart attack and the development of depressive disorders and anxiety (Lavie \& Milani, 2006; Ekers, Richards, \& Gilbody, 2008; Doyle, Conroy, McGee, \& Delaney, 2010), proving that psychological help is needed during the rehabilitation program to concretely invite patients to manage and overcome the acute event. Therefore, during this period the emotional response of the patients toward their pathology stabilizes so that they can feel both discouragement and hostility (typical in cardiac patients) - but also resignation and surrender - these in turn are able to stimulate the individuals who gain control over their behaviour.

Short-term cardiac rehabilitation has a great emotional impact on cardiac patients, influencing their perception and management of the illness. Working on emotions, through a psychological group, helps patients change their beliefs and approach the illness with a different perspective. Constant learning is stimulated together with exchange of information and sharing of doubts and concerns, this leads to a higher perception of the disease and at the same time makes possible to employ all personal resources available (Corda \& Bonella, 2009).

The presence of nursing staff has an important value

Table 3. Gender differences in Illness beliefs before $\left(T_{0}\right)$ and after $\left(T_{1}\right)$ cardiac rehabilitation.

\begin{tabular}{|c|c|c|c|c|c|}
\hline IPQ-R & Administration & $\begin{array}{c}\text { Men } \\
\text { M (SD) }\end{array}$ & $\begin{array}{l}\text { Women } \\
\text { M (SD) }\end{array}$ & $\mathbf{F}$ & $\mathbf{P}$ \\
\hline Duration & $\begin{array}{l}\mathrm{T}_{0} \\
\mathrm{~T}_{1} \\
\end{array}$ & $\begin{array}{l}15.50(5.07) \\
16.57(3.93) \\
\end{array}$ & $\begin{array}{l}13.47(4.68) \\
14.10(4.88) \\
\end{array}$ & $\begin{array}{l}2.51 \\
4.80 \\
\end{array}$ & $\begin{array}{l}0.12 \\
0.03\end{array}$ \\
\hline Consequences & $\begin{array}{l}\mathrm{T}_{0} \\
\mathrm{~T}_{1} \\
\end{array}$ & $\begin{array}{l}12.44(4.15) \\
11.70(3.31)\end{array}$ & $\begin{array}{l}12.00(3.78) \\
11.90(3.59)\end{array}$ & $\begin{array}{l}0.17 \\
0.48 \\
\end{array}$ & $\begin{array}{l}0.68 \\
0.83 \\
\end{array}$ \\
\hline Personal control & $\begin{array}{l}\mathrm{T}_{0} \\
\mathrm{~T}_{1} \\
\end{array}$ & $\begin{array}{l}17.96(3.08) \\
18.53(2.43) \\
\end{array}$ & $\begin{array}{l}16.85(3.20) \\
18.10(2.19)\end{array}$ & $\begin{array}{l}1.77 \\
0.47 \\
\end{array}$ & $\begin{array}{c}.18 \\
0.49\end{array}$ \\
\hline Treatment control & $\begin{array}{l}\mathrm{T}_{0} \\
\mathrm{~T}_{1} \\
\end{array}$ & $\begin{array}{l}15.72(1.93) \\
15.89(2.07)\end{array}$ & $\begin{array}{l}14.90(2.40) \\
16.05(1.76) \\
\end{array}$ & $\begin{array}{l}2.19 \\
0.08 \\
\end{array}$ & $\begin{array}{l}0.14 \\
0.78\end{array}$ \\
\hline Illness coherence & $\begin{array}{l}\mathrm{T}_{0} \\
\mathrm{~T}_{1} \\
\end{array}$ & $\begin{array}{l}13.57(3.41) \\
14.28(2.57) \\
\end{array}$ & $\begin{array}{l}12.70(3.42) \\
13.35(3.26)\end{array}$ & $\begin{array}{l}0.92 \\
1.54 \\
\end{array}$ & $\begin{array}{l}0.34 \\
0.22 \\
\end{array}$ \\
\hline Timeline cyclical & $\begin{array}{l}\mathrm{T}_{0} \\
\mathrm{~T}_{1} \\
\end{array}$ & $\begin{array}{l}5.44(2.76) \\
5.40(2.17) \\
\end{array}$ & $\begin{array}{l}5.70(2.13) \\
6.55(2.28) \\
\end{array}$ & $\begin{array}{l}0.13 \\
3.78 \\
\end{array}$ & $\begin{array}{l}0.71 \\
0.06 \\
\end{array}$ \\
\hline Emotional representations & $\begin{array}{l}\mathrm{T}_{0} \\
\mathrm{~T}_{1}\end{array}$ & $\begin{array}{l}9.42(4.35) \\
8.85(3.31)\end{array}$ & $\begin{array}{l}11.50(4.32) \\
11.55(4.37)\end{array}$ & $\begin{array}{l}3.21 \\
7.64\end{array}$ & $\begin{array}{c}0.77 \\
0.007\end{array}$ \\
\hline
\end{tabular}

Table 4. Gender differences in self-efficacy in the management of positive and negative emotions before $\left(T_{0}\right)$ and after $\left(T_{1}\right)$ cardiac rehabilitation.

\begin{tabular}{|c|c|c|c|c|c|}
\hline $\begin{array}{l}\text { Self-efficacy scale in the management } \\
\text { of positiveand negative emotions }\end{array}$ & Administration & $\begin{array}{c}\text { Men } \\
\text { M (SD) }\end{array}$ & $\begin{array}{l}\text { Women } \\
\text { M (SD) }\end{array}$ & $\mathbf{F}$ & $\mathbf{P}$ \\
\hline Negative emotions & $\begin{array}{l}\mathrm{T}_{0} \\
\mathrm{~T}_{1}\end{array}$ & $\begin{array}{l}30.27(5.94) \\
30.91(7.29)\end{array}$ & $\begin{array}{l}28.55(7.32) \\
27.90(4.72)\end{array}$ & $\begin{array}{l}1.02 \\
2.88\end{array}$ & $\begin{array}{l}0.31 \\
0.98\end{array}$ \\
\hline Positive emotions & $\begin{array}{l}\mathrm{T}_{0} \\
\mathrm{~T}_{1}\end{array}$ & $\begin{array}{l}30.72(5.36) \\
31.02(4.34)\end{array}$ & $\begin{array}{l}30.75(5.11) \\
30.03(5.91)\end{array}$ & $\begin{array}{l}0.25 \\
0.31\end{array}$ & $\begin{array}{l}0.98 \\
0.58\end{array}$ \\
\hline
\end{tabular}


for patients because it has allowed the connection between the psychic and the body since the nurses are the operators present with greater continuity in the various stages of rehabilitation and who can process the affects through the experience of the group (Caccamo, Ghedin, \& Marogna, 2017).

The perception of the effectiveness of the management of positive and negative emotions does not have statistic changes of great importance during rehabilitation, even though qualitatively speaking patients feel more comfortable to cope with negative emotions. Being more aware and realistic makes the patient handle both positive and negative emotions; the former deriving from the knowledge of the illness, the latter deriving from the knowledge of the consequences of a new lifestyle. Rehabilitation tries to focus its attention on the psychological support, which is a fundamental element in the frame of the management of emotions, especially the negative ones.

To conclude, the support provided during rehabilitation is useful to re-elaborate past experiences, which would have not been analysed so deeply and profoundly elsewhere. The psychological group seems an instrument useful to cure physical medical conditions, for patients affected by heart disease proves to be curative. In this setting, patients can identify both common and contrasting elements which lead to new solutions, new feedbacks and hopes (Corbella, Girelli, \& Marinelli, 2001; Whalley, Thompson, \& Taylor, 2014). The feeling of isolation the patient suffers after the acute event is contrasted by the proximity of other fellow patients in the group, who successfully help him/her to improve the relationship with his/her own disease (Marogna \& Caccamo, 2014).

\section{Conclusions}

This study encourages specialists of rehabilitation to actively collaborate to help cardiac patients face the situation in which they are involved. Moreover, it can provide useful information to both clinicians and researchers. The change in the perception of the illness inevitably activates a natural partnership with it. Heart disease is severe and dangerous; therefore, a preventive rehabilitation program is fundamental. The evaluation described above has the purpose of changing the perception and the management of the illness and, with regards to cardiac rehabilitation it allows investigating the typical characteristics of cardiac patients. These characteristics make the path to recovery a more complicated one but nevertheless aimed to wellness. All elements considered, new incentives are given to medical assistants involved in the rehabilitation program to offer improved therapeutic programs which take more variables into consideration, to personalize these programs.

Dedicating time to the perception and management of the illness helps the patient to find a functional and valuable instrument to live with her/his own disease, not only by surviving it but also by enjoying every-day life thanks to the implementation of new functional strategies.

Although this study underlines the importance of cardiac rehabilitation as a help given to the patients to accept the acute event they outlived and its consequences, it has its limits. Firstly, the absence of a control or a comparison group does not allow generalizations of the results, as it is not possible to exclude that changes are uniquely due to the passing of time. Secondly, there was a lack of a follow-up which could have allowed better understanding of the results achieved in the study, if they are stable in time or not. Lastly, another limit is given by the recruitment of patients. The patients involved in this program were those who willingly decided to get involved in the rehabilitation program without persuasion, thus intending to reach specific goals. It would be of greater interest to succeed in examining the differences between motivated patients and those who did not prove to be truly interested in joining the program and the study, so as to focus the attention on the motivations that persuade the cardiac patient to take part or not in the rehabilitation program. There are very few patients who refuse the rehabilitative path that is recommended to all. The exclusions are mainly related to: distance from home, transport difficulties especially for older non-autonomous patients and young patients who have to resume work immediately. Therefore, the absence of a checking sample of absolute necessity that could be used to compare participants with those who were not is clearly a limit, for it does not permit to standardise the results.

\section{References}

Aalto, A., Heijmans, M., Weinman, J, \& Aro, A. R. (2005). Illness perceptions in coronary heart disease: Sociodemographic, illness-related, and psychosocial correlates. Journal of Psychosomatic Research, 58(5), 393-402.

Balestroni, G., \& Giannuzzi, P. (2010). Le reazioni emozionali del paziente in riabilitazione cardiologica: analisi temporale e prospettive. Monaldi Archives of Chest Diseases, 74(1), 9-15.

Biondi-Zoccai, G., Mazza, M., Roever, L., Van Dixhoorn, J., Frati, G., \& Abbate, A. (2016). Evidence-based psychotherapy in ischemic heart disease: Umbrella review and updated meta-analysis. In A. Roncella \& C. Pristipino (Eds), Psychotherapy for Ischemic Heart Disease (pp. 131-158). Switzerland: Springer International Publishing.

Caccamo, F., Ghedin, S., \& Marogna C. (2017). La valutazione del burnout e dell'alessitimia in un gruppo di operatori in cure palliative: uno studio pilota. Giornale Italiano di Medicina del Lavoro ed Ergonomia, 39(4), 249-255.

Caccamo, F., Saltini, S., Carella, E., Carlon, R., Marogna, C., \& Sava, V. (2018). The measure of effectiveness of a shortterm 2-week intensive Cardiac Rehabilitation program in decreasing levels of anxiety and depression. Monaldi Archives for Chest Disease, 88(1), 1-4.

Caprara, G. V. (2001). La valutazione dell'autoefficacia. Costrutti e strumenti. Trento: Edizioni Erickson. 
Carlson, J. J., Norman, G. J., Feltz, D. L., Franklin, B. A., Johnson, J. A., \& Locke, S. K. (2001). Self-efficacy, psychosocial factors, and exercise behavior in traditional versus modified cardiac rehabilitation. Journal of Cardiopulmonary Rehabilitation, 21, 363-373.

Corbella, S., Girelli, R., \& Marinelli, S. (2001). Gruppi omogenei. Milano: Borla.

Corda F., \& Bonella L. (2009). Interventi psicologici in riabilitazione cardiologica. Quaderni di Villa Sandr, XVIII.

Dahlke, R. (2015). L'infarto dell'Anima. Superare burnout, boreout e depressione. Roma: Edizioni Mediterranee.

Da Vico, L., Ciompi, M., Schininà, F., Sogaro, E., Mannelli, W., \& Cortini, S. (2014). Multidisciplinarietà in riabilitazione cardiologica ed in prevenzione secondaria, dalla valutazione all'educazione terapeutica: un progetto formativo. Monaldi Archives for Chest Disease, 82, 35-42.

De Isabella, G. \& Majani, G. (2015). Psicologia in medicina: vantaggi e prospettive. Milano: Franco Angeli.

Dis, M. A. C. (2003). Linee guida per le attività di psicologia in cardiologia riabilitativa e preventiva. Monaldi Archives for Chest Disease, 60(3), 184-234.

Doyle, F., Conroy, R. M., Mcgee, H. M., \& Delaney, M. K. (2010). Depressive symptoms in persons with acute coronary syndrome: specific symptom scales and prognosis. Journal of Psychosomatic Research, 68(2), 121-130.

Ekers, D., Richards, D., \& Gilbody, S. (2008). A meta-analysis of randomized trials of behavioural treatment of depression. Psychological Medicine, 38, 611-623.

Freitas, P. D., Haida, A., Bousquet, M., Richard, L., Mauriège, P., \& Guiraud, T. (2011). Short-term impact of a 4-week intensive cardiac rehabilitation program on quality of life and anxiety-depression. Annals of Physical and Rehabilitation Medicine, 54(3), 132-143.

French, D. P., Cooper, A., \& Weinman, J. (2006). Illness perceptions predict attendance at cardiac rehabilitation following acute myocardial infarction: A systematic review with metaanalysis. Journal of Psychosomatic Research, 61, 757-767.

Ghedin, S., Semi, A., Caccamo, F., Caldironi, L., Marogna, C., Piccione, F., ... Vidotto, G. (2017). Emotionally focused couple therapy with neurodegenerative diseases: a pilot study. The American Journal of Family Therapy, 45(1), 15-26.

Giardini, A., Majani G., Pierobon A., Gremigni P., \& Catapano I. (2007). Contributo alla validazione italiana dell'IPQ-R. Giornale di Medicina del Lavoro ed Ergonomia, 29(1), A64-A74.

Grace, S. L., Krepostman, S., Brooks, D., Arthur, H., Scholey, P., Suskin, N., ... Stewart, D. E. (2005). Illness perceptions among cardiac patients: relation to depressive symptomatology and sex. Journal of Psychosomatic Research, 59(3), 153-160.

Griffo, R. (2010). La cardiologia riabilitativa: dall'appropriatezza clinica a quella organizzativa. Giornale Italiano di Cardiologia, 11(5 Suppl 3), 109S-115S.

Griffo, R., Urbinati, S., Giannuzzi, P., Jesi, A. P., Sommaruga, M., Sagliocca, L., ... Familiari, M. G. (2008). Linee guida nazionali su cardiologia riabilitativa e prevenzione secondaria delle malattie cardiovascolari: sommario esecutivo. A cura del Gruppo di lavoro dell'Agenzia per i Servizi Regionali, dell'Istituto Superiore di Sanità - Piano Nazionale Linee Guida - e del Gruppo Italiano di Caadiologia Riabilitativa e Preventiva (GICR). Giornale Italiano di Cardiologia, 9(4), 286-297.

Herring, M. P., Puetz, T. W., O’Connor, P. J., \& Dishman, R. K. (2012). Effect of exercise training on depressive symptoms among patients with a chronic illness: a systematic review and meta-analysis of randomized controlled trials. Archives of Internal Medicine, 172(2), 101-111.

Keteyian, S. J., Squires, R. W., Ades, P. A., \& Thomas, R. J. (2014). Incorporating patients with chronic heart failure into outpatient cardiac rehabilitation: Practical recommendations for exercise and self-care counselling - A clinical review. Journal of Cardiopulmonary Rehabilitation and Prevention, 34(4), 223-232.

Lavie, C. J., \& Milani, R. V. (2006). Adverse psychological and coronary risk profiles in young patients with coronary artery disease and benefits of formal cardiac rehabilitation. Archives of Internal Medicine, 166(17), 1878-1883.

Lespérance, F., \& Frasure-Smith, N. (2000). Depression in patients with cardiac disease: a practical review. Journal of Psychosomatic Research, 48(4-5), 379-391.

Leventhal, H., \& Cameron, L. (1987). Behavioral theories and the problem of compliance. Patient Education and Counseling, 10(2), 117-138.

Marogna, C., \& Caccamo, F. (2014). Analysis of the process in brief psychotherapy group: the role of therapeutic factors. Research in Psychotherapy: Psychopathology, Process and Outcome, 17(1), 43-51.

Molinari, E., Compare, A., \& Parati, G. (2007). Mente e cuore. Clinica psicologica della malattia cardiaca. Milano: Springer-Verlag.

Morgan, K., Villiers-Tuthill, A., Barker, M., \& Mcgee, H. (2014). The contribution of illness perception to psychological distress in heart failure patients. BMC Psychology, $28(1), 50$.

Moss-Morris, R., Weinman, J., Petrie, K., Horne, R., Cameron, L., \& Buick, D. (2002). The revised illness perception questionnaire (IPQ-R). Psychology and Health, 17(1), 1-16.

Mozafari, A., Baharvand, A., Mohebi, S., \& Hejazi, S.F. (2016). Impact of cardiac rehabilitation on depression after percutaneous coronary intervention. Journal of Health, 7(3), 356-364.

Petrie, K. J., Jago, L. A., \& Devcich, D. A. (2007). The role of illness perceptions in patients with medical conditions. Current Opinion in Psychiatry, 20(2), 163-167.

Piepoli, M. F., Corra, U., Adamopoulos, S., Benzer, W., Bjarnason-Wehrens, B., Cupples, M., ... McGee, H. (2014). Secondary prevention in the clinical management of patients with cardiovascular diseases. Core components, standards and outcome measures for referral and delivery: a policy statement from the cardiac rehabilitation section of the European Association for Cardiovascular Prevention \& Rehabilitation. Endorsed by the Committee for Practice Guidelines of the European Society of Cardiology. European Journal of Preventive Cardiology, 21(6), 664-681.

Pogosova, N., Saner, H., Pedersen, S. S., Cupples, M. E., McGee, H., Höfer, S., ... von Känel, R. (2015). Psychosocial aspects in cardiac rehabilitation: From theory to practice. A position paper from the Cardiac Rehabilitation Section of the European Association of Cardiovascular Prevention and Rehabilitation of the European Society of Cardiology. European Journal of Preventive Cardiology, 22(10), 1290-1306.

Pourafkari, L., Ghaffari, S., Tajlil, A., Shahamfar, J., Hedayati, S., \& Nader, N. D. (2016). The impact of cardiac rehabilitation program on anxiety and depression levels after coronary artery bypass graft surgery. Cor et Vasa, 58(4), e384-e390.

Rutledge, T., Redwine, L. S., Linke, S. E., \& Mills, P. J. (2013). A meta-analysis of mental health treatments and cardiac rehabilitation for improving clinical outcomes and depression 
among patients with coronary heart disease. Psychosomatic Medicine, 75(4), 335-349.

Scholz, U., Sniehotta, F. F., \& Schwarzer, R. (2005). Predicting physical exercise in cardiac rehabilitation: The role of phasespecific self-efficacy beliefs. Journal of Sport and Exercise Psychology, 27(2), 135-151.
Whalley, B., Thompson, D. R., \& Taylor, R. S. (2014). Psychological interventions for coronary heart disease: cochrane systematic review and meta-analysis. International Journal of Behavioral Medicine, 21(1), 109-121.

Yalom, I., \& Leszcz, M. (2005). Teoria e pratica della psicoterapia di gruppo. Torino: Bollati Boringhieri. 